\title{
Engaging SMEs in Cooperation and New Forms of Learning
}

\author{
Ileana Hamburg ${ }^{1}$, Emma O. Brien ${ }^{2} \&$ Steffi Engert ${ }^{3}$ \\ ${ }^{1}$ Westfälische Hochschule Gelsenkirchen, Germany \\ ${ }^{2}$ University of Limerick, Ireland \\ ${ }^{3}$ E-Competence-Agentur, Universität Duisburg-Essen, Germany \\ Correspondence: Ileana Hamburg, Westfälische Hochschule Gelsenkirchen, Germany. E-mail: hamburg@iat.eu
}

Received: September 13, $2013 \quad$ Accepted: October 14, 2013 Online Published: October 17, 2013
$\begin{aligned} & \text { doi:10.5539/cis.v7n1p1 } \\ & \text { URL: http://dx.doi.org/10.5539/cis.v7n1p1 }\end{aligned}$

\begin{abstract}
Globalization has strong if contradictory impacts on SMEs. The sharp increase of worldwide competition in recent decades weakened SMEs right across the board. At the same time, globalization offers many new opportunities and the importance of SMEs has increased. Opportunties include the potential to act as collaborators in multi-enterprise consortia, for international clients and partners. Their importance has increased because of their specific potential, such as high specialization and the ability to react faster than big enterprises. Therefore, it is important for such companies to take up the challenge to operate on a global scale. To be able to play this role, SMEs have to tackle change and develop their learning processes on a far-reaching scale. If the triangle and interplay of continuous learning, knowledge management and new technologies, is key in making or breaking companies as well as national and supranational entities (such as the EU), it is important new means of addressing these areas, particularly through the use of ICT are explored. While ICT and especially web 2.0 applications - social networks, blogging, web repositories and shared resources, modern learning platforms have great potential to support and enable SMEs in their drive towards competitiveness, the realization of this potential is by no means automatic. Success depends on a strategic approach, technical skills and facilities. This paper takes a closer look at the situation of European SMEs and presents findings from recent European projects identifying the ongoing problems in the adoption of new forms of learning. Secondly the paper discusses learning approaches and web-based technologies particularly suitable for SMEs.
\end{abstract}

Keywords: SME, web, informal learning, problem-based learning, social learning, mentoring

\section{Introduction}

Small and medium sized companies (SMEs) are an important economic sector contributing to national output, to the creation of jobs, acting as a nursery for future large firms and for expanding micro enterprises. To hold their own and expand further under conditions of globalization, in particular permanent shifts in the international division of labor and markets which are driven by continuous rapid technological change, they have to find and defend their niche while developing the ability to re-invent themselves again and again. The key factors for their survival and growth are strategic acumen, qualification and re-qualification through learning, and the optimization of processes. These are in turn based on learning and the management of knowledge. SMEs are faced with significant pressures to survive particularly in their initial set up stages; this influences the use of informal and experiential learning strategies.

The situation and needs of SMEs differ significantly from those of big enterprise. They are often undercapitalized, employing ICT only in a limited way, such as doing accounts, searching the Internet, perhaps having a static presence. Learning is typically 'learning by doing' on the job. Because they work on a limited work force, making time for learning is often a problem; existing knowledge remains often tacit, undocumented, and unshared.

Because of the constraints on their ability to invest in learning - such as sending people off to seminars and employing expensive trainers - learning needs to be integrated into the SMEs working environment directly as much as possible to reduce the time resources spent away from work thus affecting their productivity. As policy-makers and researchers have noted for decades in political and scientific recommendations, ICT-based learning offers the answer to SME needs. E-Learning through its flexibility and ease of access is seen as an enabler of lifelong learning with its potential to transform how and when employees learn, and to act as a 
catalyst of change and integration. E-Learning supports flexible and informal types of learning very well, which are typically preferred by SMEs. However, training and development using new forms of e-learning are still largely regarded as an expense rather than an investment by SMEs managers.

New opportunities for SMEs are opened up by the concept of Web 2.0 (O`Reilly, 2005), which facilitates a new level of interaction, information sharing and collaboration. The use of social media, such as blogging, social networks, web services, and new generation e-learning further improves the ability of learners to socially interact with the technology used (communication with technology) and learn through its use. The need for SMEs to find new ways of cooperation through networking is assisted by these technologies and technologically enabled cooperation forms, for example technology-enabled Communities of Practice (CoP) (Wenger, 1998; Engert \& Petschenka, 2011a; Hamburg, 2011a).

These communities are learning environments where individuals share a domain of interest and knowledge and learn to increase their knowledge through formal and informal learning methods, in order to solve problems interactively (Hall \& Hamburg, 2009). Their potential is further heightened, if they are supported by social media based environments, such as Facebook-like networks, open e-learning environments (such as the newly improved Moodle) and others. The social learning theory proposed by Albert Bandura added a social element to learning and is close to communities (De Witt \& Gangus, 2011). These approaches are relevant for SMEs, because they fit in so well into their habit of learning within their working environment. Social learning contributes directly to the development of interaction, cooperation, communication and conflict-management skills, CoPs link learning and knowledge management into one continuous process.

This paper takes a closer look at the situation of European SMEs and presents findings from recent European projects identifying the ongoing problems in the adoption of new forms of learning. Secondly it discusses learning approaches and web-based technologies particularly suitable for SMEs.

\section{Learning Problems in European SMEs}

Small and medium-sized enterprises are socially and economically important, representing $99 \%$ of all enterprises in the EU. They provide millions of jobs and contribute to entrepreneurship and innovation (ECORYS, 2012). Through the downturn in recent years SMEs have retained their position as the backbone of the European economy. However the difficult economic environment continues to pose severe challenges to them. More and more they need to have sustainable, innovative business strategies supported by flexible learning approaches and new technologies in place. But the acceptance and ability to implement this are still very much absent in wide circles of SME management.

In this context, the readiness of SMEs to use new forms of learning (particularly e-Learning) and cooperation is an aspect to be considered. In the project ReadiSME (Hall \& Hamburg, 2011; Rosenberg, 2000), European SMEs have been interviewed and case studies have been carried out to evaluate their readiness for new technologies and forms of learning. The majority of companies responded that they understand the importance of lifelong learning (LLL) but they are still not prepared to take on new forms of learning as a competitive tool. In ReadiSME and in previous European projects like Ariel, SIMPEL (Beer et al., 2006, 2008) and Net Knowing 2.0 (www.netknowing.com), barriers to training and e-learning were identified:

- Lack of deep analysis to identify skill shortages and learning needs of staff to achieve business objectives.

- Existing learning culture does not support cooperative or social learning.

- Lack of manager knowledge or awareness about of the effectiveness of new forms of learning.

- Shortage of skilled staff and so a lack of time and motivation to test new learning methods.

- Insufficient financial possibilities to develop/train for new forms of learning and technologies.

- Reliance on quick informal methods of "learning by doing", when the need arises.

- Lack of suitable electronic content and appropriate modes of training.

- Lack of attractive training offers supporting specific business needs.

- Lack of understanding of training as a top managerial concern, delegation to departmental level or external training provider.

- Problems with management of missing knowledge; low level of knowledge-transfer to improve the effectiveness of their work tasks.

- Lack of knowledge or understanding of policies of communication and cooperation in research and production. 
- Inefficient use of new methods and technologies for sharing and creating knowledge and for development (updating) of innovative skills.

All of these aspects require an improvement of corporate learning to assure fast transfer of knowledge, to allow SMEs to develop the required competences, i.e. abilities to respond with flexibility, to be business oriented and to develop the relevant business knowledge at the lowest possible cost to the organization.

\section{Forms of Learning}

\subsection{Informal Learning}

Jay Cross is "a champion of informal learning used in SMES and systems thinking" (www.jaycross.com). Jay's calling is to help people to improve their performance on the job and their satisfaction in life. His philosophies underline that companies can use informal learning combined with other forms to (Cross, 2006):

- Increase sales by making product knowledge instantly searchable.

- Improve knowledge worker productivity.

- Transform an organization from near-bankruptcy to record profits.

- Generate fresh ideas and increase innovation.

- Reduce stress, absenteeism, and health care costs.

- Invest development resources where they will have the most impact.

- Increase professionalism and professional growth.

- Cut costs and improve responsiveness with self-service learning.

One approach which seems useful in the context of improving learning and cooperation within SMEs and external experts is that of Communities of Practice (CoPs) oriented to learning and social aspects. CoPs are made up of voluntary members who share knowledge, ideas and interests and who act as mentors to each other. They offer new opportunities for knowledge management and learning processes by using novel forms of social interaction. CoPs are situated somewhere between a team work structure and loose contact between various interested actors (Hamburg, 2011b). Today CoPs are increasingly efficient particularly when supported by web-based environments. In the project SIMPEL, for example, a CoP using Moodle as a platform worked on two levels - national and EU partners - to elaborate models and strategies for sustainable learning in SMEs between project partners and external experts (Hamburg et al., 2008). In ReadiSME, Moodle was also used for a CoP of the wider project community to

- elaborate a Model framework for LLL Readiness in SMEs.

- gather useful ICT tools for e-learning in SMEs (Engert \& Petschenka, 2011a).

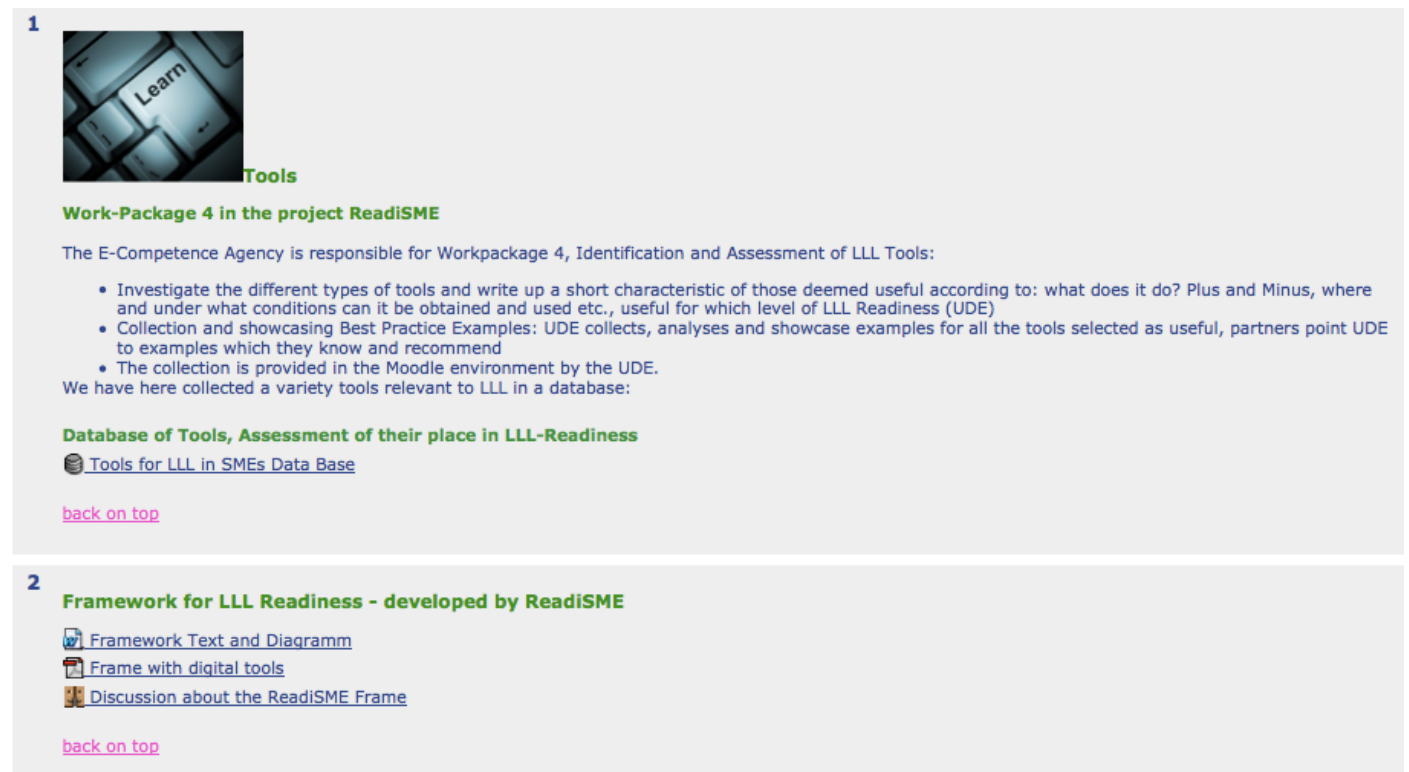

Figure 1. http://moodle.uni-duisburg-essen.de/course/view.php?id=2308 
At present, most European SMEs act alone in facing their training problems. A successful and suitable solution would be for SMEs to build/join CoPs in different forms, in order to share knowledge, apply best practice in workplace design and to develop business-oriented models of training. CoPs might serve regional integration (multiple players including SME), competitiveness on branch level (e.g. automotive enterprise plus suppliers), SMEs complementing each other, SMEs sharing trainings facilities/courses, to name just a few.

In the following sections we present some other forms of learning suitable for SMEs and supported by CoPs (Hamburg, 2012a; O'Brien et al., 2011; De Witt \& Gangus, 2011) like problem-based learning and social learning.

\subsection{Problem Based Learning}

Problem based learning is a holistic, student centered approach to learning that integrates several learning theories (Sendag, 2010), authentic learning, active learning, and social learning. Learners direct their own learning and a mentor facilitates the learner in defining, researching, developing relevant content and solving problems. It is largely used in teaching medical students such as doctors and nurses but is beginning to be adopted in other areas.

Problem based learning has been proven to develop higher order thinking and critical thinking skills. There are many different approaches to PBL (Barrow, 1986; Jonassen, 1997; Wood, 2003; Hemlo-Silver) however little research has been done into the most effective methods in terms of learner success (Huag, 2011). In addition PBL has yet to be adopted outside academic contexts. PBL would be an excellent method of training for SMEs. It allows the learner to develop skills relevant to the needs of the company, it is conducted in a work based environment, it provides them with the skills to sustain the company beyond the initial training, it is low cost and it directly solves problems for the SME providing an immediate return (Bell, 2010; Walters \& Sirotak, 2011).

Donnelly (2010) highlighted that little is known about the use of technology in Problem based learning. However after conducting a study in an academic context of the use of CoPs for PBL he found that CoPs provided an opportunity to enhance collaboration and extend face to face time with mentors and peers. In a business environment PBL, by using mentoring, $\mathrm{CoP}$ and social media can be used to provide an opportunity for communication between the mentor and mentee and to work with peers (or experts inside and outside the company) to find potential solutions to the problem or approaches to solving the problem.

\subsection{Social Learning}

The explosive growth of social media technologies is due in large to the way in which they amplify and extend behavior that existed long before the Internet was even invented: conversing, sharing, collaborating, and exchanging information (http://fredcomm.com/S=0/services/detail/social_media_social_learning). Social media fills a human need and supports social learning; it allows employees to learn by connecting with each other in a wider circle than would be possible without technology. Social learning means learning by observing, conversing, asking in formal and informal forms. It facilitates collaboration, and community-building within and across organizations.

Social media based on Web 2.0 and 3.0 (Hamburg, 2011a, 2012a) offer the premises for a fast acquisition of knowledge and support and facilitiates social learning within the communities. The technical skills needed to use social media are rather low.

Social media tools like Internet forums, weblogs, social blogs, micro blogging, wikis, podcasts, sharing of pictures, video, rating and social bookmarking are easy to use and can help to create a more dynamic community and provide an on-going conversation benefiting the members. 
Table 1. Overview of PBL and social learning

\begin{tabular}{|c|c|c|}
\hline & Problem-based learning & Social learning \\
\hline Characteristics & $\begin{array}{l}\text { Collaborative; authentic; contextualised; } \\
\text { holistic; user-generated content }\end{array}$ & $\begin{array}{l}\text { Participation; collaboration; } \\
\text { user-generated content }\end{array}$ \\
\hline $\begin{array}{l}\text { Didactic } \\
\text { potentials }\end{array}$ & Self-directed learning; collaborative learning & $\begin{array}{l}\text { Learning in social networks and } \\
\text { communities; informal learning; } \\
\text { collaborative learning }\end{array}$ \\
\hline Limitations & $\begin{array}{l}\text { Lack of a 'proven' theory for PBL in an } \\
\text { organizational context. Sharing of content } \\
\text { between organizations }\end{array}$ & Traditional corporate cultures \\
\hline Applications & $\begin{array}{l}\text { Micro-blogging; social networking; } \\
\text { social tagging }\end{array}$ & $\begin{array}{l}\text { Micro-blogging; social networking; } \\
\text { social tagging;wikis }\end{array}$ \\
\hline Technologies & Community platforms & $\begin{array}{l}\text { Community platforms; } \\
\text { micro-blogging tools }\end{array}$ \\
\hline
\end{tabular}

Source: De Witt and the authors.

\subsection{MOOCs}

An emerging form of learning which might be suitable for SMEs is MOOC. MOOC (massive open online course http://en.wikipedia.org/wiki/Massive_open_online_course) are online courses aimed at large-scale interactive participation and open access via the web. In addition to traditional course materials such as videos, readings, and problem sets. MOOCs provide interactive user forums that help build a community for the students, professors, and teaching assistants (TAs).

MOOCs come in two basic varieties XMOOCS and cMOOCs. This stands for extended MOOC and connectivist MOOC respectively. Roughly the two varieties offer individual self-learning or pre-fabricated materials (Xmooc) vs. a more constructivist model, where learners learn through the connection/community and change/augment the learning materials (cMooc). But of course there are overlaps as well (Blended MOOC).The emphasis in both forms is on self-learning.

It is at the moment not entirely clear, how MOOCs will develop further. There are interesting aspects especially for European SMEs, which so far have not really been reached. MOOCs have no less than a true revolutionary potential of smoothing out hierarchies based on differential access to quality education (Gillani, 2013), particularly when Ivy Leagues and other prestigious institutions of learning make their content available. On the other hand, big international e-learning corporations are getting ready to divide the global market between themselves in a new drive for profits and a position to determine what learning and which contents are relevant for assessments. At the moment, however, everybody is still struggling with finding a viable business model for MOOCs (The Economist, 2013).

An earlier list of connectivist principles from Siemens (2005) shows the pedagogy behind MOOCs (mostly cMOOCs) and - incidentally - that not the educational concepts are new, but just the form of delivery:

- Learning and knowledge rest in diversity of opinions.

- Learning is a process of connecting specialized nodes or information sources.

- Learning may reside in non-human appliances.

- Capacity to know more is more critical than what is currently known.

- Nurturing and maintaining connections is needed to facilitate continual learning.

- Ability to see connections between fields, ideas, and concepts is a core skill.

- Currency (accurate, up-to-date knowledge) is the intent of all connectivist learning activities.

- Decision making is itself a learning process. Choosing what to learn and the meaning of incoming information is seen through the lens of a shifting reality. While there is a right answer now, it may be wrong tomorrow due to alterations in the information climate affecting the decision.

It is suggested that connectivist MOOCs support collaborative dialogue and knowledge, which are better than models adopting other approaches (http://en.wikipedia.org/wiki/Massive_open_online_course). However the 
c-variety is often more costly and labor intensive than the $\mathrm{x}$-variety.

\section{Mentoring}

Mentoring (originated from the poem The Odyssey) is a human research development approach and together with suitable learning methods (Kram, 1985) it may address successfully aspects like knowledge gaps and skill shortages (Hamburg, 2013). An existing member of staff or an external collaborator guide newcomers or less-experienced people in a task to develop professional skills, attitudes and competencies. Also, people with special needs can be helped by mentoring to integrate into work life. Mentoring is a key process for knowledge management. In a process of transferring tacit knowledge and retaining expertise within the organization, mentoring can also help the mentee to become a recognized and accepted member of the community, by passing on corporate vision and values and improving his grasp of corporate networking (http://www.knowledge-management-tools.net/mentoring.html). Recently, mentoring has been proven as an efficient way to develop more productive workers and so the approach has been adopted by many organizations. A Gartner report shows that the most improvements were achieved in salaries, promotion and retention.

There is a broad range of mentoring relationships, which can be used in companies ranging from informal or spontaneous mentoring to highly structured and planned mentoring. Informal mentoring is created by a special interest in the mentee by the mentor, for example when the mentee has been identified as potential employee. This form of mentoring is particularly suitable for people with special needs.

Formal mentoring takes place, when the relationship is supported by the organization in a system of mentoring, from which more participants can benefit. Formal mentoring programs as a well-established way to retain and transfer knowledge (http://www.knowledge-management-tools.net/mentoring.html). Companies should therefore consider implementing formal mentoring relationships and mentor training as an investment in the future knowledge stock of the organization.

The goal of mentoring staff from SMEs is to improve job performance by increasing employees' capability to manage their own performance, emphasizing trust, experience, and supervision, to facilitate performance in the organization, to support retention and leadership development.

Mentors will listen to the mentees' views and problems in their work, share with mentees their thinking and experience and give advice. Mentoring supports the development of autonomous skills, judgment, personal and professional mastership, expertise, trust and the development of self-confidence over time (Kram, 1985; Hamburg \& Marian, 2012).

Mentors will not make decisions for mentees. Mentees must make decisions for themselves.

According to organizations practicing mentoring, social media is useful for communication with mentors. Social media web-platforms support social learning; forums, blogs, virtual market places, extend traditional face-to-face mentoring by allowing mentoring to take place over distance and in different time periods. This approach supports also formal mentoring processes, which are more accepted by organizations, because they see direct benefits and more mentees are mentored simultaneously.

But there are also problems in using general social media. The mentor might read information not appropriate for the relationship mentor-mentee, about absences or even sexual activities of the mentees, etc. This can cause mentees to lose trust in the mentors.

At the workshop organized during the project Net Knowing 2.0, SMEs from Germany proposed a route map for the successful deployment of a coaching and mentoring program in the specific context of a SME environment:

- Putting the specific working environment into context.

- Researching the role played by the organizational culture or "climate" in the development, maintenance and success of the SME.

- Determining real qualification needs of the staff before starting the mentoring process.

- Determining the knowledge gaps and identifying which of them might be minimized by a mentoring system.

- Demonstrating that a mentoring intervention has real benefits in this context by not being bureaucratic.

- Being a process based on trust, experience, and supervision and informal learning.

- Identifying barriers to effective mentoring/coaching.

- Determining issues that need to be incorporated within the mentoring/coaching intervention, if it is to be successful. 
- Qualifying coaches and mentors for different forms of working and learning.

- If necessary, using big companies to find mentors (learning consultants).

In the projects Net Knowing 2.0 and DIMENSAAI (www.dimensaai.eu) ICT supported platforms have been developed to facilitate different forms of learning and mentoring. Web 2.0 services and social media applications have been integrated (www.cop.netknowing.eu; platform.dimensaai.eu). Tiki Wiki CMS Groupware has been used. Tiki Wiki CMS Groupware, originally and more commonly known as TikiWiki or simply Tiki, is a free and open source wiki-based, content management system written primarily in PHP and distributed under the GNU Lesser General Public License (LGPL) license (https://de.tiki.org/).

ICT supported learning during the mentoring process also has a number of benefits including:

- Provision of 24 hour access for training material and communication.

- Accessible wherever the Internet is available.

- Provision of a platform that does not require face-to-face communication.

- Learning assessment and progress of the mentor/mentee relationship can be monitored.

On the platform, training material is available, but also a discussion forum for each module enables learners and trainers/experts/mentors to exchange ideas and to add to the environment. The forums allow learners to provide feedback (anonymously, if desired) to the experts. It also enables them to pose queries which other participants, or the experts, can answer.

\section{Conclusions}

In this paper it has been advocated that it is necessary for companies, particularly for SMEs to be flexible and fast familiarise themselves with new working environments and technologies. It highlighted that there is a demand for a practical, work based approach to learning in SMEs that allows the company to obtain the relevant skills and knowledge quickly at a low cost. Informal learning has been widely adopted by SMEs but has not yet reached its full potential. By integrating the use of Web 2.0 tools with connectivist approaches and aligning training with problem based learning through the support of mentors will allow SMEs to develop the relevant content and knowledge easily through the access of external expertise while at the same time solving internal problems in the organization. Mentoring is an efficient way of transferring strategic knowledge before it leaves the organization when the person retires or leaves. Mentoring supports better employee engagement, inclusion and diversity and a culture of collaborative learning characterized by trust.

With the emergence of low-cost, high-performance devices coupled with universal Internet accessibility, simple applications (apps), new forms of learning like social learning have materialised which could be easily integrated into training within SMEs at a low cost with a maximum ROI.

\section{Acknowledgement}

This paper described work within the Ariel and SIMPEL projects supported by the EU within the e-Learning initiative and the innovation transfer projects ReadiSME, NetKnowing 2.0 and DIMENSAAI, sponsored by the LLL Leonardo da Vinci sub-programme.

\section{References}

Bandura, A. (1977). Social Learning Theory. General Learning Press.

Barrows, H. S. (1986). A taxonomy of problem-based learning methods. Medical Education, 20, 481-486. http://dx.doi.org/10.1111/j.1365-2923.1986.tb01386.x

Beer, D., Busse, T., Hamburg, I., Mill, U., \& Paul, H. (2006). E-learning in European SMEs: Observations, Analyses \& Forecasting. Proceedings of the ARIEL Final Conference, 08. 11. 2005 in Brussels. Waxmann Verlag.

Beer, D., Busse, T., Hamburg, I., \& Oehler, C. (2008, April). Improving eLearning practices in SMEs. Brussels. In Proceedings of the SIMPEL final conference (Vol. 14, p. 2008).

Bell, S. (2010). Project-based learning for the 21st century: Skills for the future. The Clearing House, 83(2), 39-43. http://dx.doi.org/10.1080/00098650903505415

Cross, J. (2007). Informal learning: Rediscovering the natural pathways that inspire innovation and performance. Wiley.com.

De Witt, C., \& Ganguin, S. (2011). Kommunikation in Serious Games. Digitale Lernwelt-Serious games: Einsatz 
in der beruflichen Weiterbildung (pp. 97-108).

Donnelly, R. (2006). Blended problem-based learning for teacher education: Lessons learnt learning. Media and Technology, 31(2), 93-116. http://dx.doi.org/10.1080/17439880600756621

Donnelly, R. (2010). Harmonizing technology with interaction in blended problem-based learning. Computers \& Education, 54(2), 350-359. http://dx.doi.org/10.1016/j.compedu.2009.08.012

ECORYS. (2012). EU SMEs in 2012: at the crossroads. Annual report on small and medium-sized enterprises in the $E U, 2011 / 12$. Retrieved from c.europa.eu/enterprise/policies/sme/.../2012/annual-report_en.pdf

Engert, S., \& Petschenka, A. (2011a). Communities of Practice - A promising approach to LLL in SMEs. International Conference on Life Long Learning for Competitiveness, Employability and Social Inclusion: proceedings of the ReadiSME final conference (pp. 23-30). Craiova, Rumänien. Editura Universitaria Craiova.

Engert, S., \& Petschenka, A. (2011b). Moodle for business uses in small SMEs. International Conference on Life Long Learning for Competitiveness, Employability and Social Inclusion: proceedings of the ReadiSME final conference (pp. 16-23). Craiova, Rumänien. Editura Universitaria Craiova.

Engert, St., Hamburg, I., \& Terstriep, J. (2011). Promoting online education for new working environments in companies. In U. Demiray \& S. Sever (Eds.), Marketing online education programs: frameworks for promotion and communication (pp. 337-358). Hershey, PA: Information Science Reference.

Gillani, N. (2013, March 11). MOOC-sourcing for Social Good. Retrieved September 12, 2013, from http://www.ssireview.org/blog/entry/mooc_sourcing_for_social_good

Hall, T., \& Hamburg, I. (2011). Readiness for knowledge management, methods and environments for innovation. In E. O'Brien, S. Clifford \& M. Southern (Eds.), Knowledge management for process, organizational and marketing innovation: tools and methods (pp. 1-15). Hershey: Information Science Reference.

Hall, T., \& Hamburg, I. (2009). Learning in social networks and Web 2.0 in SMEs' continuing vocational education. International Journal of Web Based Communities, 5(4), 593-607. http://dx.doi.org/10.1504/IJWBC.2009.028092

Hamburg, I. (2011a). Learning solutions and social media based environments for companies. In Life long learning for competitiveness, employability and social inclusion: international conference (pp. 31-37). Craiova, Romania. Editura Universitaria. http://dx.doi.org/10.5772/29986

Hamburg, I. (2011b). Instant learning on demand and communities. Problems of education in the 21st Century, $28,33-41$.

Hamburg, I. (2012a). Innovative e-learning solutions and environments for small and medium sized companies (SMEs). In P. Ghislandi (Ed.), Elearning: theories, design, software and applications (pp. 53-72). Rijeka: InTech.

Hamburg, I. (2012b). Using informal learning, e-learning, and cooperation in SMEs. International journal of e-business development, 2, 28-31.

Hamburg, I. (2013). Facilitating learning and knowledge transfer through mentoring. In CSDU 2013: 5th International Conference on Computer Supported Education (p. 4). Aachen, Germany, Lissabon: Science and Technology Publications.

Hamburg, I., Engert, S., Petschenka, A., \& Marin, M. (2008, March). Improving E-Learning 2.0-based Training Strategies of SMEs through Communities of Practice. IASTED International Conference on Human-Computer Interaction. Innsbruck.

Hamburg, I., \& Marian, M. (2012). Supporting knowledge transfer and mentoring in companies by e-learning and cloud computing. In D. Chiu, E. Popescu \& Q. Li (Eds.), ICWL 2012: the 11th International Conference on Web-based Learning (pp. 91-101). Sinaia, Romania; local workshop proceedings. Craiova: Univ. of Craiova.

Hmelo, C. E. (1998). Problem-based learning: Effects on the early acquisition of cognitive skill in medicine. The Journal of the Learning Sciences, 7(2), 173-208. http://dx.doi.org/10.1207/s15327809j1s0702_2

Hung, W. (2011). Theory to reality: A few issues in implementing problem-based learning. Educational Technology Research and Development, 59(4), 529-552. http://dx.doi.org/10.1007/s11423-011-9198-1 
Jonassen, D. H. (1997). Instructional design models far well-structured and ill-structured problem solving learning outcomes. Educational Technology Research and Development, 45(1), 65-94. http://dx.doi.org/10.1007/BF02299613

Kram, K. (1985). Mentoring at work: Developmental relationships in organizational life. Scott, Foresman \& Company, Glenview.

Massive open online course. (n.d.) Retrieved from http://en.wikipedia.org/wiki/Massive_open_online_course

O'Brien, E., Clifford, S., \& Southern, M. (2011). Knowledge management for process, organizational and marketing innovation: tools and methods. Hershey.

O'Reilly, T. (2005). What is Web 2.0. Design patterns and Business models for the next generation of Software. Retrieved from http://www.oreillynet.com/lp/a/6228

Rosenberg, M. J. (2000). The e-Learning readiness survey: 20 key strategic questions you and your organization must answer about the sustainability of your e-Learning efforts. Retrieved from http://books.mcgrawhill.com/training/elearning/elearning_survey.pdf

Sendag, S., \& Ferhan Odabas, H. (2010). Effects of an online problem based learning course on content knowledge acquisition and critical thinking skills. Computers \& Education, 53, 132-141. http://dx.doi.org/10.1016/j.compedu.2009.01.008

Siemens, G. (2005). Connectivism: A learning theory for the digital age. In International TikiWiki CMS Groupware. Retrieved March 1, 2010, from http://info.tiki.org

The Economist. (2013, July 20). The Attack of the MOOCs. Retrieved September 12, 2013, from $\mathrm{http} / / / \mathrm{www}$.economist.com/news/business/21582001-army-new-online-courses-scaring-wits-out-traditionaluniversities-can-they

Walters, R., \& Sirotiak, T. (2011). Assessing the effect of project based learning on leadership abilities and communication skills. The 47th ASC Annual International Conference Proceedings.

Wenger, E. (1998). Communities of Practice: Learning, Meaning and Identity. Cambridge MA: Cambridge University Press. http://dx.doi.org/10.1017/CBO9780511803932

Wood, D. F. (2003). ABC of learning and teaching in medicine: Problem based learning. British Medical Journal, 326, 328-330. http://dx.doi.org/10.1136/bmj.326.7384.328

\section{Copyrights}

Copyright for this article is retained by the author(s), with first publication rights granted to the journal.

This is an open-access article distributed under the terms and conditions of the Creative Commons Attribution license (http://creativecommons.org/licenses/by/3.0/). 